MAGNARTO प्राम

(4)

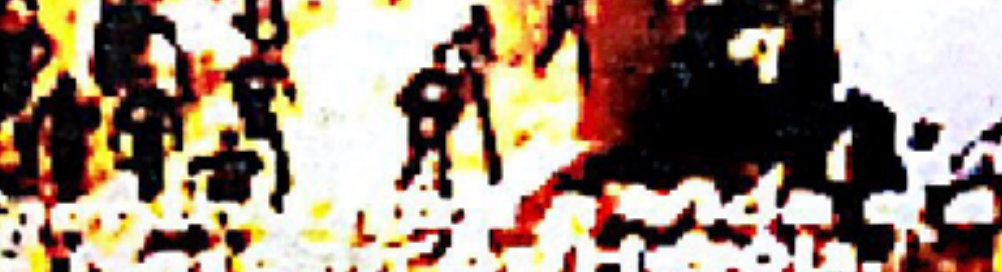

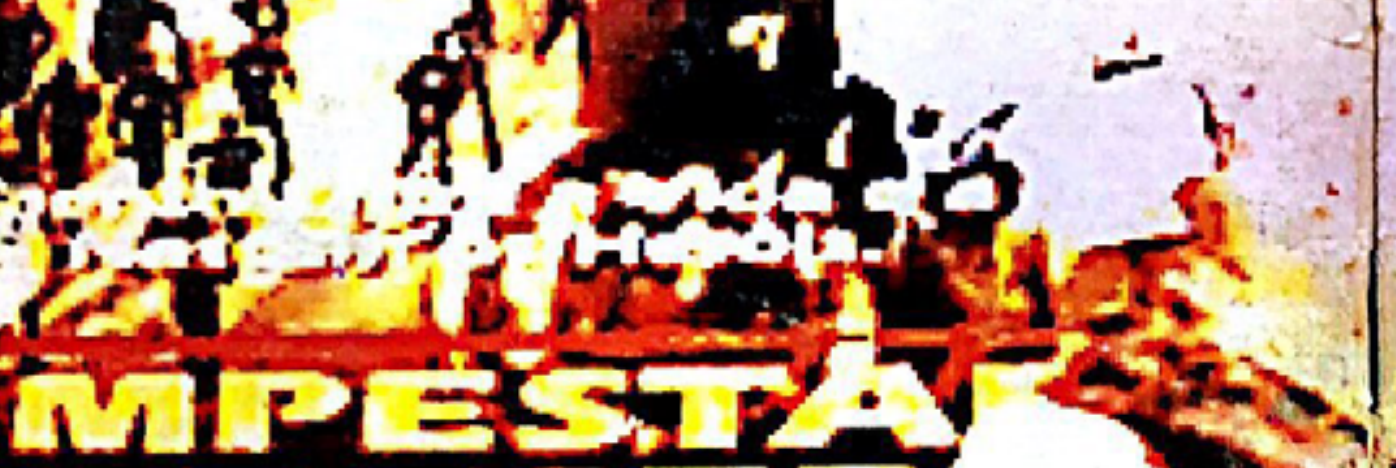

$2 D S T=15$

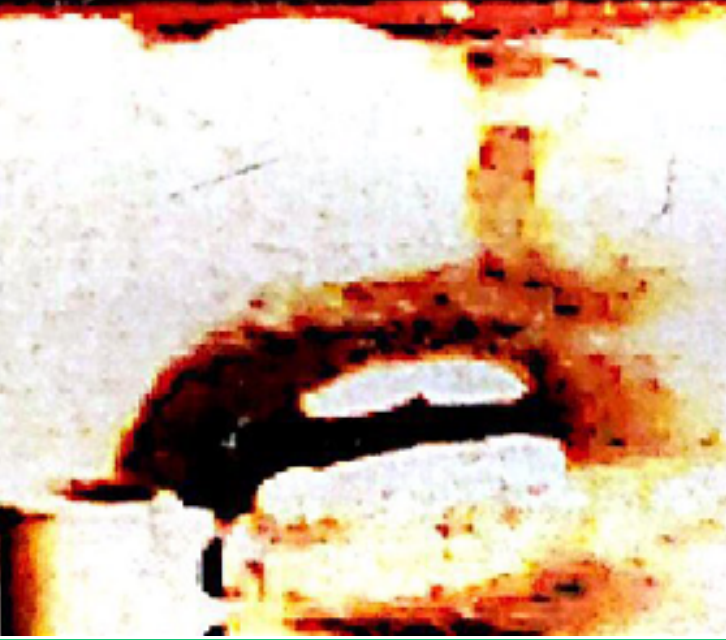

A estética do imaginário no cinema

Demian Garcia e André A. Medeiros P. 94

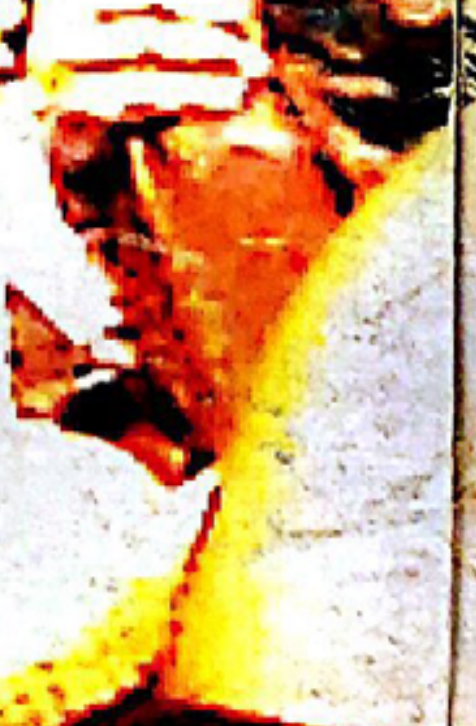

$+$

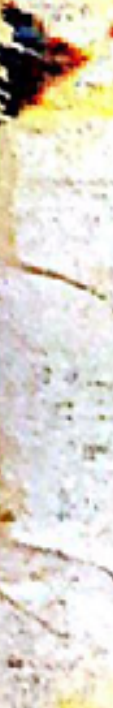

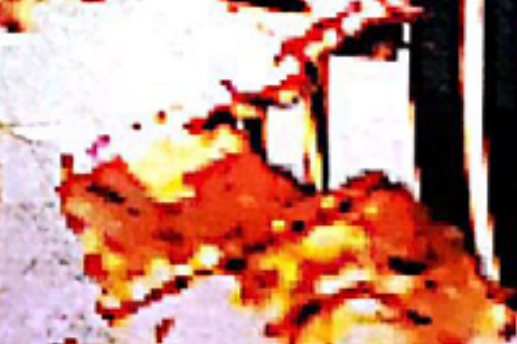

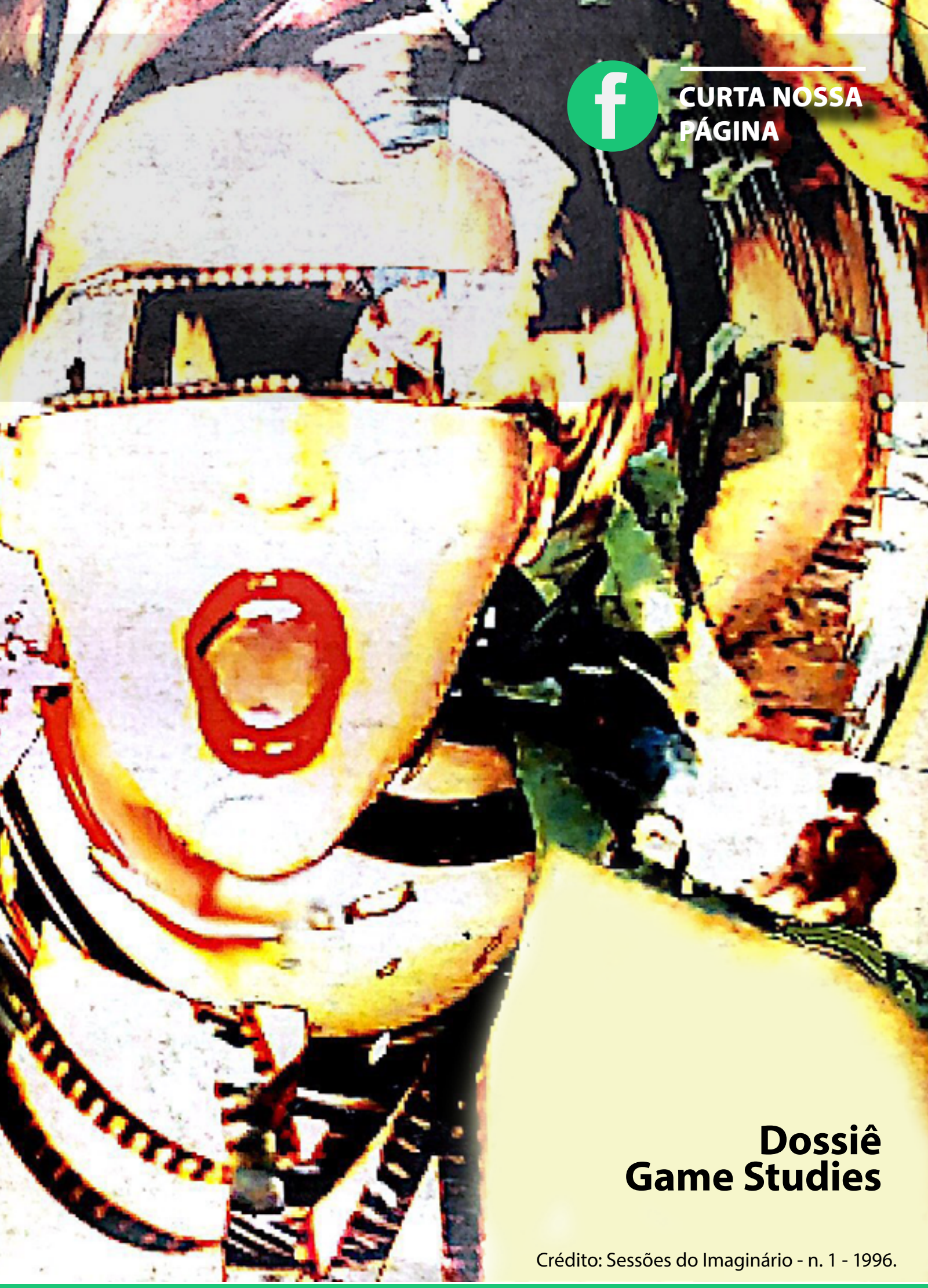

Materialidades fílmicas, magia e montagem

Ednei de Genaro

P. 112

Videogames, transgressão e criatividade no Brasil

Emmanoel Ferreira 


\section{Cinema noir clássico e contemporâneo: influências e construção do imaginário para o gênero}

\section{Cinema noir classic and contemporary: influences and construction of imaginary for gender}

\section{Alexandre Rossato Augusti ${ }^{1} \square$}

Nathalia Lopes da Silva ${ }^{2}$

\section{Resumo}

O presente trabalho busca investigar como o filme noir clássico influencia o cinema contemporâneo reconhecido como neonoir, e descobrir como essas produções podem estabelecer imaginários sobre a temática do crime. Para tanto, observamos mais detalhadamente os filmes Pacto Sinistro (Strangers on a train), de Alfred Hitchcock (1951) e Cães de Aluguel (Reservoir Dogs), de Quentin Tarantino (1992). Utilizamos autores como Borde e Chaumeton (1958), Mascarello (2006), Silva (2006), Silver e Ursini (2004) e Maffesoli (2001), com destaque para Rose (2002) no que se refere especificamente à metodologia adotada nesse trabalho. Dentre as principais conclusões, evidenciamos que os elementos do noir clássico aparecem nos filmes noir atuais como uma releitura, com diferentes significados ${ }^{3}$.

\section{Palavras-chave}

Cinema noir; imaginário; Pacto Sinistro; Cães de Aluguel.

\section{Abstract}

The present work seeks to investigate how classic film noir influences contemporary cinema, recognized as neonoir, and to discover how these productions can establish imaginaries on the theme of crime. For that, we look more closely at the films Strangers on a train, by Alfred Hitchcock (1951) and Reservoir dogs, by Quentin Tarantino (1992). We use authors such as Borde and Chaumeton (1958), Mascarello (2006), Silva (2006), Silver and Ursini (2004) and Maffesoli (2001), with particular emphasis on Rose (2002), based on her method. Among the main conclusions, we show that the classic noir elements appear in the current noir films as a rereading, with different meanings.

\section{Keywords}

Film noir; imaginary; Strangers on a train; Reservoir dogs.

209 PORTO ALEGRE | v. 22 | n. 38 | 2017 | p. 209-219 DOI: http://dx.doi.org/10.15448/1980-3710.2017.2.29722 Sessões do Imaginário 


\section{Algumas orientações sobre}

\section{o cinema noir}

Os filmes noir representam bem mais que apenas produções identificadas com a violência, o crime e o sexo, como já apontam Silver e Ursini (2004). O cinema noir foi um gênero que rompeu com as tradições do cinema americano da época através de suas características influenciadas pela literatura, o expressionismo alemão e a psicanálise. Defende-se que algumas produções baseadas no gênero e que surgiram após seu período clássico [1941 a 1958, conforme defendem Heredero e Santamarina (1996), e Silver e Ursini (2004)], sendo consideradas contemporâneas, podem ser denominadas neonoir.

O trabalho apresentado a seguir busca descobrir de que forma o filme noir se manifesta em filmes contemporâneos que têm potencial noir e, portanto abordam o crime em suas histórias. Para isto, investigamos alguns significados com os quais as principais características do filme noir clássico surgem no gênero contemporâneo, e a capacidade que as produções noir e neonoir possuem de estabelecer imaginários sobre a temática criminal e através de quais elementos isto ocorre. Como objetos desta análise, escolhemos duas produções, uma pertencente ao período do noir clássico e outra do contemporâneo. As obras selecionadas foram Pacto Sinistro (Strangers on a train, Alfred Hitchcock, 1951) e Cães de Aluguel (Reservoir Dogs, Quentin Tarantino, 1992), respectivamente.

Os filmes foram escolhidos por se tratarem de dois clássicos do cinema (num sentido mais geral do termo clássico), pelo fato de possuírem características específicas do estilo de cada diretor e serem produções inovadoras para suas épocas. Hitchcock é aclamado como um mestre da sétima arte e Tarantino é reverenciado como prodígio da atualidade. Suas produções compartilham alguns pontos em comum, tais como a utilização exacerbada da violência e a frequente atuação dos diretores em seus próprios filmes. Em Pacto Sinistro, Hitchcock aparece por um breve momento embarcando no trem e, em Cães de Aluguel, Tarantino é um dos ladrões que morre logo no começo da trama.

O crime, a violência e a morte podem ser considerados os protagonistas dos filmes noir. As produções, compreendidas mais tarde como cinema noir, tratavam essa temática do crime em função do momento histórico e econômico dos EUA no período, decorrente do pós-guerra e da crise financeira mundial. Os filmes teriam servido como um meio de denunciar as consequências que este momento conturbado trouxe à sociedade, como afirma Mascarello.

Metaforicamente, o crime noir seria o destino de uma individualidade psíquica e socialmente desajustada, e, ao mesmo tempo, representaria a própria rede de poder ocasionadora de tal desestruturação. A caracterização eticamente ambivalente da quase totalidade dos personagens noir, o tom pessimista e fatalista, e a atmosfera cruel, paranóica e claustrofóbica dos filmes, seriam todos manifestação desse esquema de representação do crime como espaço simbólico para a problematização do pós-guerra (Mascarello, 2006, p. 181).

Borde e Chaumeton (1958) estabelecem sete elementos que caracterizariam o noir. São eles: um crime; a história contada através da perspectiva dos criminosos, às vezes superando a da polícia; a visão invertida das autoridades tradicionais e a corrupção policial; a femme fatale ("mulher fatal" que causa a ruína/morte de um bom homem); alianças e lealdades instáveis; violência bruta; e motivação e mudança em complôs bizarros. São esses os elementos mapeados nas obras escolhidas para a análise.

É extenso o número de elementos fílmicos adotados pelo noir. Mattos (2001) destaca algumas dessas características.

[...] ângulos exagerados; primeiríssimos planos; câmera oblíqua; linhas horizontais cruzadas com verticais aumentando a impressão de clausura psicológica e física; variações no posicionamento da luz chave (key light), atenuante (fill light) ou contraluz (backlight) para produzir esquemas inusitados de luz e sombras adequados à criação do clima de paranóia, delírio e ameaça; corpos delineados em silhuetas dramáticas contra um fundo iluminado; filmagem de cenas noturnas realmente de noite (night-for-night) tornando o céu mais negro e ameaçador; reflexos no espelho sugerindo "o outro lado" do personagem ou sublinhando os temas recorrentes de perda ou confusão de identidade; estranhos pontos luminosos sobre os rostos do herói para injetar-lhe uma aparência sinistra ou de demência; heroínas fotografadas de maneira sedutora e outras estratégias visuais aparecem com obsessiva repetição (Mattos, 2001, p. 46).

\section{Noções sobre imaginário e sua aplicabilidade ao cinema}

O imaginário já foi conceituado por vários autores. A complexidade do termo e as suas várias interpreta- 
ções propiciam que confusões se formem em torno da sua definição. Segundo Silva (2006, p. 7), a palavra imaginário tornou-se muito popular no final do último século, o que proporcionou "um deslocamento conceitual inaceitável".

Baseando-se em Silva (2006), pode-se conceituar o imaginário como um "reservatório" onde são adicionadas imagens, lembranças, experiências, o que é imaginado, e as "leituras da vida", sendo que este, através de uma estrutura que pode ser individual ou grupal, "sedimenta um modo de ver, de ser, de agir, de sentir e de aspirar ao estar no mundo" (Silva, 2006, p. 12).

A amplitude do conceito é ressaltada por Maffesoli (2001), que entende o imaginário como "o estado de espírito que caracteriza um povo", concluindo que este pertence a uma atmosfera que não pode ser materializada, constituindo-se de uma aura. $\mathrm{O}$ autor percebe $\mathrm{o}$ imaginário como "uma construção mental, que se mantém ambígua, mas não quantificável" (Maffesoli, 2001, p. 75).

O imaginário é entendido por Silva (2006), como uma forma de reconhecimento. O autor sistematiza a construção destes imaginários como essencialmente por identificação, agregação, distorção e contágio.

A construção do imaginário individual se dá, essencialmente por identificação (reconhecimento de si no outro), apropriação (desejo de ter o outro em si) e distorção (reelaboração do outro para si). O imaginário social estrutura-se principalmente por contágio: aceitação do modelo do outro (lógica tribal) disseminação (igualdade na diferença) e imitação (distinção do todo por difusão de uma parte) (Silva, 2006, p. 13).
As teorias do imaginário já foram aplicadas a diferentes campos do conhecimento. Silva (2006, p. 15) elucidaria essa flexibilidade teórica assegurando que "o imaginário não é um determinismo". Trazendo-o para o âmbito desta pesquisa, este, por vezes, já foi relacionado às teorias cinematográficas. Metz, um dos teóricos sobre esta relação, afirma que "[...] o cinema, não oferecendo nenhuma presença real, é constituído de representantes, de significantes, de imaginários, no duplo sentido - usual e técnico - da palavra [...]" (Metz apud Aumont, 2005, p. 119). É possível relacionar a temática do imaginário ao filme noir, pois este cinema visava através de seus elementos, e da temática criminal, transmitir a situação de uma época. Maffesoli (apud Silva 2006, p. 14) entende que "o imaginário é determinado pela ideia de fazer parte de algo. Partilha-se uma filosofia de vida, uma linguagem, uma atmosfera, uma ideia de mundo, uma visão das coisas, na encruzilhada do racional e do não racional".

\section{Perspectiva metodológica}

O método utilizado para analisar os filmes Pacto Sinistro e Cães de Aluguel tem amparo na proposição metodológica de Diane Rose, no capítulo Análise de imagens em movimento, do livro Pesquisa qualitativa com texto, imagem e som, de Martin Bauer e George Gaskell, de 2002. Esta técnica de análise para produtos audiovisuais foi elaborada para investigar representações da loucura na televisão britânica em 1992. As fases utilizadas na realização desta pesquisa e na referida metodologia são: seleção, transcrição, codificação e tabulação.

Conforme as orientações de Rose, temos a seleção como a primeira etapa e que consiste na separação do conteúdo a ser estudado, o que sugere uma triagem que deve ser realizada de acordo com o tempo e com a área a ser pesquisada e a orientação teórica da pesquisa. Os itens que não são incluídos têm relevância equivalente aos que irão nortear a mesma. Segundo a autora, "[...] o que deixar fora é tão importante quanto o que vai se incluir, e irá afetar o restante da análise" (Rose, 2002, p. 346).

Quanto à transcrição, a sua função é organizar um conjunto de dados que possam produzir uma análise detalhada e uma codificação. Compõe a descrição do material selecionado na etapa anterior e, para que este processo se torne possível, as unidades de análise (UA) devem ser definidas. Podem ser linhas, sentenças, parágrafos ou tomadas de câmera, de acordo com a fundamentação teórica da pesquisa a ser realizada. A transcrição é realizada em duas colunas - a da esquerda contém o aspecto visual da história e a da direita é uma transcrição literal do material verbal (Rose, 2002).

A codificação constitui a terceira etapa do método, em que as unidades de análise são substituídas por códigos, muitas vezes representados por sinais gráficos. Codificadas as informações, todas são tabuladas, resultando em uma série de informações quantitativas. A autora, que finaliza assim a orientação para análise, ainda dispõe a metodologia em passos, expostos no quadro 1.

Para aplicar o método desenvolvido por Rose (2002) ao corpus deste trabalho, primeiramente realizamos a seleção das unidades de análise. $O$ critério para essa escolha foi a presença das características clássicas do filme noir estabelecidas por Borde e Chaumeton (1958) nas duas produções, com o intuito de viabilizar a comparação dos pontos em que há mais elementos, conforme a avaliação dos autores deste trabalho, que poderiam agir como formadores de imaginários sobre a temática do crime e evidenciar a forma como o noir clássico influenciou o cinema noir contemporâneo. 


\section{Passos na análise de textos audiovisuais}

- Escolher um referencial teórico e aplica-lo ao objeto empírico.

- Selecionar um referencial de amostragem - com base no tempo ou no conteúdo.

- Selecionar um meio de identificar objeto empírico no referencial de amostragem.

- Construir regras para a transcrição do conjunto de informações - visuais e verbais.

- Desenvolver um referencial de codificação baseado na análise retórica e na leitura preliminar do conjunto de dados: que inclua regras para a análise, tanto do material visual, como do verbal; que contenha a possibilidade de desconfirmar a teoria; que inclua a análise da estrutura narrativa e do contexto, bem como das categorias semânticas.

- Aplicar o referencial de codificação aos dados, transcritos em uma forma condizente com a translação numérica.

- Construir tabelas de frequência para as unidades de análise, visuais e verbais.

Quadro 1: Passos na análise de textos audiovisuais. Fonte: Rose (2002).

- Aplicar estatísticas simples, quando apropriadas.

- Selecionar citações ilustrativas que complementem a análise numérica.

$\mathrm{Na}$ fase da transcrição estão organizados os quadros 2 e 3 , nos quais foram decupadas as cenas escolhidas. Os quadros foram divididos em duas colunas, onde à esquerda se encontra o material visual (ambientação, motivos iconográficos ${ }^{4}$, flashbacks ${ }^{5}$, ângulos de câmera) e à direita se encontra descrito o material verbal e sonoro das unidades de análise (diálogos e sonoplastia). Na sequência dos quadros, vêm a interpretação e a análise descritiva da seleção.

A tabulação, que é de ordem numérica, não pareceu adequada à temática desta pesquisa. Devido ao seu âmbito interpretativo, por sua fundamentação nas teorias do imaginário, e ao fato de a análise descritiva se adaptar melhor aos objetivos traçados para o trabalho, optamos por não realizar esta etapa. Baseando-nos em Rose, esta destaca que "Algumas das técnicas apresentadas devem ser adaptadas para outros conteúdos [...]" (2002, p. 362). A fase quantitativa também é melhor aplicável em produtos audiovisuais de curta duração, o que não é o caso desta análise, que tem como objeto de estudo dois longas-metragens.

\section{Exercício de análise}

Exemplificamos a análise realizada a partir de cenas dos filmes escolhidos, fazendo referência a um dos elementos apontados por Borde e Chaumeton (1958): o crime.

No caso de Pacto Sinistro, a trama do filme é baseada em uma proposta incomum feita por Bruno Antony (personagem interpretada por Robert Walker) a Guy Haines (Farley Granger), quando se encontram pela primeira vez em um trem a caminho de Washington. Guy 
é um tenista profissional, que deseja obter o divórcio de sua esposa Miriam para casar-se com Anne Morton (Ruth Roman), filha de um senador. Bruno tem conhecimento da situação em que se encontra Guy e lhe propõe um intercâmbio de assassinatos. Este mataria Mirian (mulher de Guy, interpretada por Kasey Rogers) e em troca o tenista acabaria com a vida do pai de Bruno. Bruno acredita que desta forma a polícia não poderia descobrir quem cometeu os crimes, pois não haveria ligações entre os mandantes. Contudo, Bruno considera que o pacto foi selado, mata Mirian e passa a exigir que Guy cumpra com a sua parte no trato. Ao perceber que Guy não cumprirá o acordo, Bruno resolve incriminá-lo colocando o isqueiro com as iniciais de Guy, (que estava em seu poder, pois o tenista esquecera ao emprestá-lo no trem) na cena do crime.

A narrativa de Cães de Aluguel conta a história de seis membros de um bando, reunidos pelo gângster Joe Cabot (personagem interpretada por Lawrence Tierney) para roubar uma remessa de diamantes de uma joalheria. Joe dá codinomes aos comparsas, que não se conhecem, a fim de que uns não saibam os verdadeiros nomes dos outros, são eles: Mr. Pink (personagem interpretada por Steve Buscemi), Mr. White (ou Larry, interpretada por Harvey Keitel) ${ }^{6}$, Mr. Brown (interpretada por Quentin Tarantino), Mr. Blue (Ou Eddie, interpretada por Edward Bunker), Mr. Orange (Freddy, interpretada por Tim Roth) e Mr. Blonde (ou Vic Vega, interpretada por Michael Madsen).

\section{O crime - Pacto Sinistro}

Bruno vai até Metcalf, cidade natal de Guy e onde mora Mirian. Ele a segue até o parque de diversões. Mirian está acompanhada de dois rapazes e é seguida por Bruno em todos os lugares do parque. A esposa de Guy percebe a presença de Bruno, mas acredita que ele está tentando conquistá-la. Mirian e os rapazes resolvem andar no carrossel, Bruno os segue e se senta em um lugar atrás de Mirian. A câmera capta o movimento e se posiciona a frente dos dois, o que dá a impressão de que Bruno a persegue, literalmente. Em seguida, os rapazes e Mirian sobem em um barco para ir ao "túnel do amor", e são seguidos por Bruno. Ao entrarem no túnel, a câmera não capta mais a imagens das personagens, mas somente de suas sombras na parede. Quando a silhueta de Bruno se aproxima a de Mirian, ela grita estridentemente, o que causa um momento de suspense, característico de Hitchcock. Contudo, logo um plano geral mostra a saída do túnel e o barco em que está Mirian. Os seus gritos se misturam a risos e o rapaz que a acompanha faz cócegas nela. Momentos depois o barco de Bruno sai do túnel. As duas embarcações são deixadas em uma ilha do parque e Mirian corre a frente dos rapazes que chamam por ela. É o momento em que esta encontra Bruno entre as árvores.

\begin{tabular}{l|l}
\hline \multicolumn{1}{c}{ Dimensão Visual } & \multicolumn{1}{c}{\begin{tabular}{c} 
Dimensão Verbal/Sonora7 \\
\hline $\begin{array}{l}\text { Mirian corre entre as árvores, em direção à câmera (que está } \\
\text { parada) e depara-se com Bruno, este se encontra situado } \\
\text { fora de quadro. }\end{array}$
\end{tabular}} \\
$\begin{array}{l}\text { A mão de Bruno aparece na imagem em primeiro plano, } \\
\text { coberta por uma luva, segurando o isqueiro de Guy, para } \\
\text { que a chama ilumine o rosto de Mirian. }\end{array}$ & $\begin{array}{l}\text { Bruno: O seu nome é Mirian? } \\
\text { Mirian: Pois sim. Como é que...? }\end{array}$ \\
$\begin{array}{l}\text { Bruno surge na tela e deixa o isqueiro cair. Quando começa } \\
\text { a estrangular Mirian, os óculos dela também caem. }\end{array}$ & \\
\hline $\begin{array}{l}\text { Plano médio dos óculos na grama ao lado do isqueiro. } \\
\text { Big Close em uma das lentes, que reflete a imagem } \\
\text { distorcida de Bruno estrangulando Mirian, e, em seguida, } \\
\text { deixando seu corpo deitado na grama e observando-o por } \\
\text { alguns segundos. }\end{array}$ & \\
\hline $\begin{array}{l}\text { Plano médio que mostra os cabelos de Mirian, o isqueiro de } \\
\text { Guy e os óculos quebrados. Novamente Bruno está } \\
\text { localizado fora do alcance da câmera ("fora de campo") e } \\
\text { somente a sua mão aparece para pegar os óculos. }\end{array}$ & \\
\hline $\begin{array}{l}\text { Plano detalhe no isqueiro, que Bruno também recolhe do } \\
\text { chão. }\end{array}$ & \\
\hline
\end{tabular}

Quadro 2: Transcrição do elemento "O crime". Fonte: Silva (2013). 


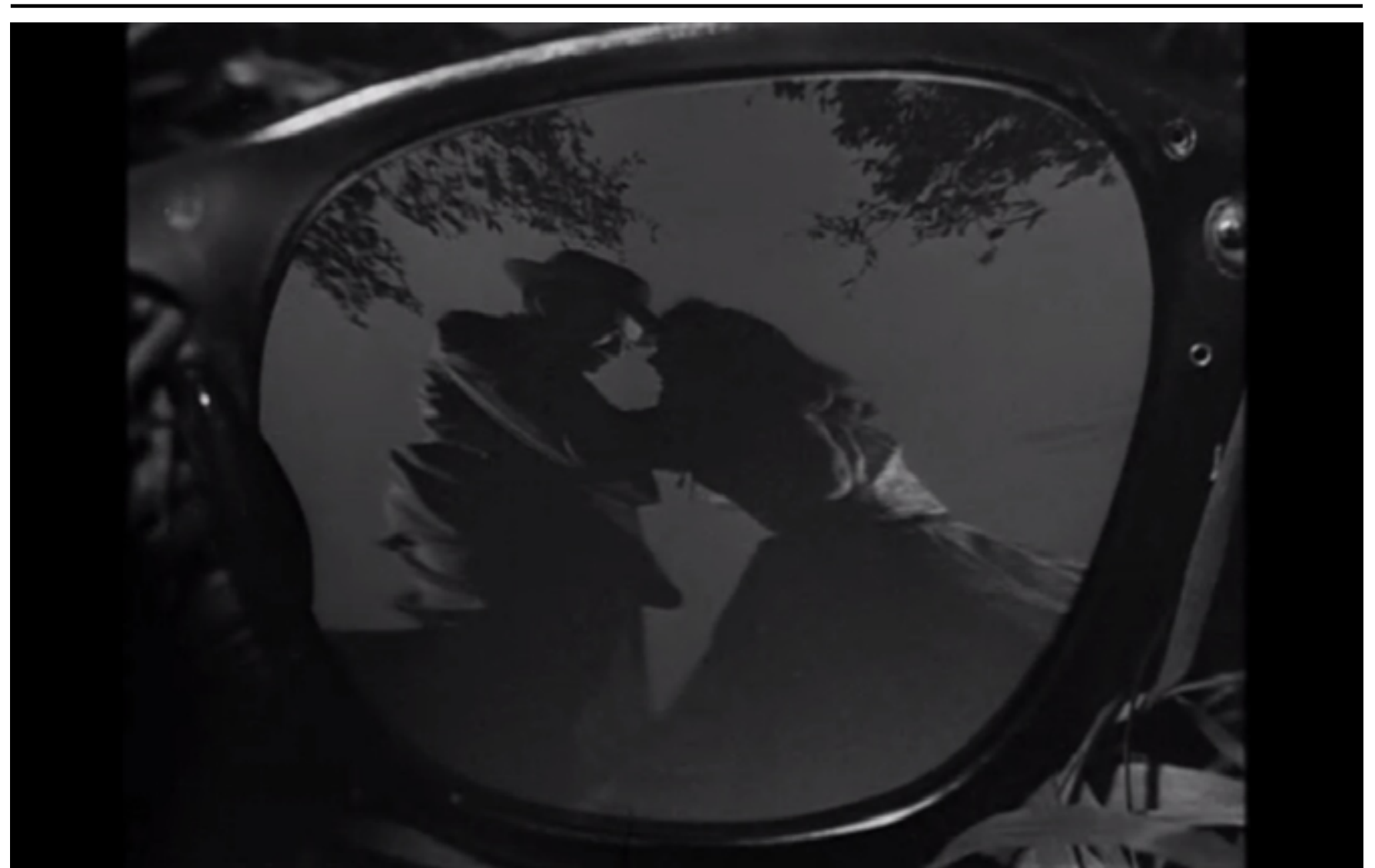

Figura 1: $O$ assassinato de Mirian refletido através da lente em um big close que deforma a imagem, bem ao estilo impressionista. Fonte: frame do filme Pacto Sinistro (Hitchcock, 1951).
Hitchcock utilizou vários recursos para oferecer uma estética noir ao assassinato de Mirian. A influência do expressionismo alemão, através do crime refletido pelas lentes, o isqueiro destacado por planos detalhe e a presença de sombras foram alguns dos elementos utilizados nesta composição. Na cena, o espelhismo é um recurso para mostrar o que está fora de campo através de um big close que deforma a imagem. Segundo Nazário (1983), no expressionismo cenas como esta são mostradas através de elementos que servem de mediadores, como reflexos, entretanto este recurso que serviria como um amenizador acaba realçando "o escândalo dos fatos".

As sombras também são elementos herdados pelo noir dos filmes expressionistas e representam o lado obscuro. Elas eram atribuídas a personagens que compactuavam com o mal e a morte, e geralmente viviam na escuridão, de acordo com Nazário (1983).

Na cena do túnel, é possível observar que a imagem da sombra de Bruno se aproxima da de Mirian, ao mesmo tempo em que ela grita, o que provoca o suspense. No imaginário do público, como destaca Nazário, inconscientemente a sombra conota maldade, o que nos leva a pensar que algum crime aconteceu.

A personagem Bruno, que representaria o lado obscuro na trama, aparece nas sombras em vários momentos do filme, inclusive quando vai até a casa de Guy noticiar a morte de Mirian. Nesta ocasião, é interessante percebermos outra metáfora, pois Bruno chama Guy para a escuridão ao lhe contar o que ocorreu. Entende-se que este coloca Guy entre sombras tanto no âmbito físico quanto no imaginário, pois o tenista se vê enredado em uma trama perigo- 
sa e da qual não vê escapatória.

$O$ isqueiro é um objeto que toma uma importância fundamental nesta ocasião, sendo a sua inserção na cena proposital e simbólica. Literalmente, ele representa a prova que pode incriminar Guy, mas no imaginário do psicopata ele simboliza a presença do tenista no local do crime, como se ele estivesse ali, pois Bruno realmente acredita que Guy cometeu o crime.

\section{O crime - Cães de aluguel}

Mr. White (Larry) é o primeiro a chegar ao armazém (lugar de encontro do grupo após o crime) carregando Mr. Orange (Freddy) que foi baleado e está perdendo muito sangue. Mr. Orange pede a Mr. White que o leve para um hospital. Ele tenta acalmá-lo e promete que Joe chamará um médico quando chegar. Mr. Pink chega em seguida, afirmando que havia um traidor no bando. Mr. White então o convida para conversar em outra sala.

O crime de Cães de Aluguel é um golpe a uma joalheria, contudo em nenhum momento do filme ele é mostrado. A única maneira com que o público pode tomar conhecimento sobre como tudo aconteceu é através dos relatos dos criminosos. Nesta sequência, Mr. White e Mr. Pink discutem o que ocorreu e no final da trama é possível perceber que Mr. Pink tinha razão. Para Baptista (2010) a decisão de não mostrar o assalto torna a palavra das personagens, essencialmente subjetiva, predominante sobre a aparente objetividade das imagens. As situações anteriores ao golpe e após ele são mostradas de forma fragmentada e não linear por meio de flashbacks. Isto ajuda o espectador a entender a história.

A intenção dos criminosos em cometer o crime perfeito é algo muito presente nos filmes noir, contudo, como afirma Augusti (2013), o seu fracasso

\begin{tabular}{|c|c|}
\hline Dimensão Visual & Dimensão Verbal/Sonora \\
\hline $\begin{array}{l}\text { A câmera enquadra um cesto de lixo, e outros objetos no cháo de } \\
\text { uma das salas do armazém. }\end{array}$ & $\begin{array}{l}\text { Mr. PInk: O que eu estou fazendo aqul? Năo estava gostando } \\
\text { disso. }\end{array}$ \\
\hline $\begin{array}{l}\text { Com um movimento da direlta para esquerda, em diagonal, ela } \\
\text { passa a mostrar Mr. White no banheiro limpando as măos, parado } \\
\text { ao final de um corredor e conversando com Mr. Pink (fora de } \\
\text { campo). }\end{array}$ & $\begin{array}{l}\text { Mr. Pink: Devia ter recusado, mas nunca acredito em mim. É a } \\
\text { mesma coisa quando compro fumo. Náo confio no cara, mas } \\
\text { quero acreditar. Porque se náo está mentindo vale a pena. } \\
\text { Ouando sinto isso num trabalho devia cair fora. Mas năo, aceitei } \\
\text { pelo maldito dinheiro! }\end{array}$ \\
\hline
\end{tabular}

A câmera continua parada e Mr. White caminha de um lado para [som de objetos sendo quebrados]

outro. Mr. Pink continua fora de campo e há ruidos que dão a Mr. White: Agora já foi. Precisa se acalmar. Está calmo? entender que ele estivesse quebrando algo. [som de Mr. Pink chutando algo]

Mr. Pink: Estou calmo.

Mr. White: L ave o rosto

Mr. Pink surge à frente da câmera, que continua parada e distante, Mr. White: Respire fundo. Relaxe, fume urn cigarro. e lava o rosto. Mr. White caminha até a porta que leva ao saláo do Mr. Pink: Parei de fumar.

armazém, lugar onde está Mr. Orange baleado e espia paráá. Em Mr. White: Está bern.

seguida volta para o banheiro para conversar com Mr. Pink sobre Mr. Pink: Você tem um?

o assalto. Mr. White oferece um cigarro a Mr. Pink.

Mr. Pink: Obrigado.

Plano médio mostra Mr. White acendendo o cigarro de Mr. Pink Mr. White: Ok. Vamos repassar o que aconteceu. Estávamos lá e com um Isqueiro. Os dois conversam um de frente para o outro e tudo la bem. Dal disparou o alarme. Eu me virel e os tiras estavam um espelho, ao lado de Mr. White, reflete a sua imagem. lá, cheqaram num piscar de olhos. E todos se apavoraram, o Blonde começou a atirar.

\section{Mr. Pink: Năo está correto.}

Mr. White: Por que náo?

Mr. Pink: Ok, os policiais não apareceram quando soou o alarme. Só quando o Blonde começou a atirar em todo mundo.

Mr. White: Quando disparou, eu os vi.

Mr. Pink: Náo foi táo rápido, só apareceram quando Blonde ficou quando o Blonde começou a atirar. Vè-se que foi uma armadilha. Vamos Mr. White.

Mr. White: Sem essa de Mr. White.

Mr. Pink: Năo diga o seu nome, năo quero saber! Eu năo vou dizer o meu.

Mr. White: Tem razáo, isso foi mal. Como conseguiu escapar? Mr. Pink: Fugi entre os tiros. Enquanto todos atiravam, dei o fora.

Quadro 3: Transcrição do elemento "O crime - 2". Fonte: Silva (2013). 
(dos criminosos) é provável nessas produções. Nesta trama as personagens expressam em várias situações a certeza de que o roubo será bem sucedido e tudo sairá exatamente como planejado, ao contrário do que na realidade acontece.

$O$ espelho que reflete a imagem de Mr. White é um motivo iconográfico utilizado pelo noir clássico e proveniente do expressionismo alemão, que representava entre seus significados a duplicidade das personagens, essas que fingiam ser algo que na verdade não eram, aparentando ser "boas", contudo logo se mostravam "más", como o psicopata Bruno, de Pacto Sinistro. Nesta sequência do filme de Tarantino, o objeto simboliza as dúvidas que envolvem a personagem, pois ao mesmo tempo em que tenta acreditar na história de Mr. Pink, Mr. White desconfia que o outro possa ser o traidor, assim como está em dúvida entre deixar Mr. Orange morrer ou levá-lo a um hospital e ser preso.

\section{Considerações finais}

Um dos elementos mais significativos nos filmes noir é o crime, pois é ele o tema central das tramas. No caso dos filmes analisados temos dois crimes distintos, um assassinato em Pacto Sinistro e um roubo de diamantes em Cães de Aluguel. No primeiro, o crime ocorre como o planejado e o verdadeiro criminoso só é descoberto porque resolve voltar ao local para se vingar. No segundo, o assalto fracassa e uma série de acontecimentos saem do controle dos ladrões. Contudo, nas duas tramas, embora os criminosos saiam livres no início, ao final acabam mortos ou presos.

É possível inferir que o noir influenciou o cinema atual quanto à forma deste retratar a realidade por meio da temática criminal. O noir procurava transmitir o sentimento vivenciado pela sociedade através da formação

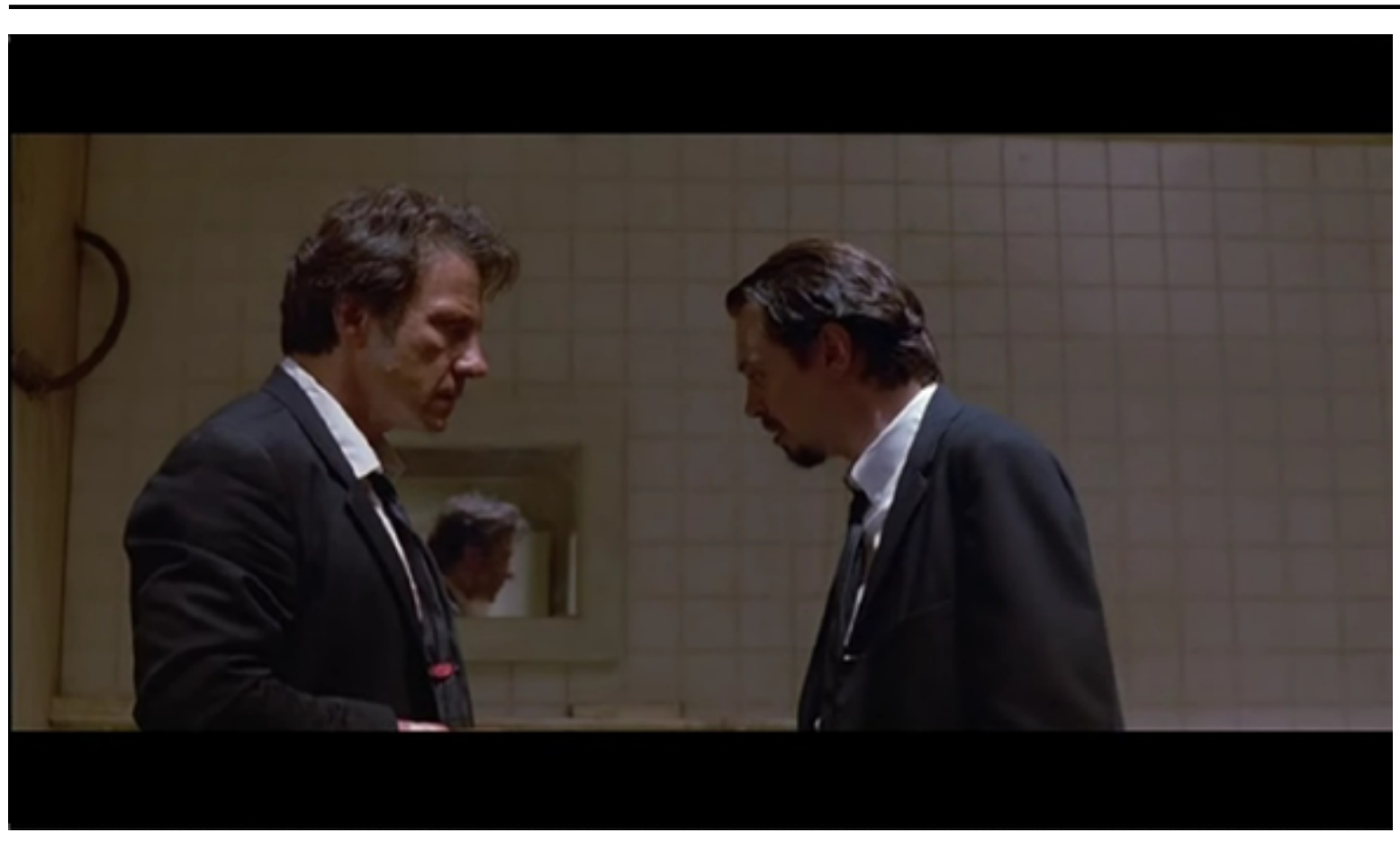

Figura 2: O espelho que reflete a imagem de Mr. White faz menção à ideia de duplicidade. Fonte: frame do filme Cães de Aluguel (Tarantino, 1992).

de imaginários, utilizando elementos como a figura da femme fatale, o estereótipo do policial ou detetive durão e ao mesmo tempo corrupto, o emprego exagerado da violência e a figura dos criminosos simpáticos. Este se valia de imaginários que já estavam presentes na sociedade e os apresentava na tela de maneira renovada, com isso criando/validando novos imaginários que são reproduzidos e reconfigurados até hoje nas produções cinematográficas consideradas neonoir.

Nas duas tramas, a polícia é retratada como incapaz de resolver os crimes e mostrada cometendo atos que ferem a ética da profissão. No noir, ela só descobre o verdadeiro criminoso porque alguém o reconheceu no dia do assassinato e Guy o persegue para recuperar o isqueiro. Na mesma produção, os policiais pré-julgam o suspeito sem que haja provas de sua culpa. No caso do neonoir, as autoridades policiais deixam quatro dos ladrões escaparem do local do assalto, um deles levando um policial, e não recuperam os diamantes. Esses acontecimentos simbolizam a ideia de que há uma sensação de insegurança em relação às autoridades nas épocas em que os filmes foram produzidos.

No cinema neonoir, a violência é utilizada de forma mais exagerada do que no noir clássico, até mesmo porque as cores nas quais os filmes são produzidos proporcionam um impacto maior às cenas com sangue. Esta é também uma das características da direção de Tarantino, o diretor costuma "pintar a tela de vermelho" sempre que um personagem se fere. A recorrência da temática nos filmes clássicos tem um significado rele-

216 PORTO ALEGRE | v. 22 | n. 38 | 2017| p. 209-219 Sessões do Imaginário 
vante para o gênero e representava a insegurança no imaginário da população quanto à atmosfera do pósguerra.

Movido por inquietações teóricas que cercam o cinema noir, como a constante dicotomia sobre este possuir ou não um sucessor moderno, este trabalho buscou responder às duas questões que nortearam o desenvolvimento da análise: descobrir como a influência do noir clássico aparece nos filmes noir contemporâneos, e de que modo essas produções são capazes de produzir imaginários sobre a temática do crime.

Os dois filmes foram submetidos aos mesmos critérios de análise para seleção das cenas, com o objetivo de observar se nas duas produções haveria a presença dos mesmos elementos e quais os significados destes em cada obra. Com base na análise descritiva e interpretativa das produções Pacto Sinistro e Cães de Aluguel, foi possível concluir que o filme noir produzido no período clássico continua deixando suas marcas no cinema mundial através do cinema neonoir. As suas características permanecem vivas nas produções, embora não mais com os mesmos significados, pois o neonoir se trata de uma releitura do seu antepassado e agrega novas técnicas ao estilo. Outra constatação é que o noir clássico, através de sua característica de agir como um espelho da realidade, possuía a capacidade de estabelecer imaginários, pois reproduzia nas telas os sentimentos vivenciados pela sociedade através de seus elementos simbólicos, validando assim imaginários, que se renovam atualmente nas produções neonoir.

Ao realizarmos as comparações, após a análise, destaca-se que a maioria das características do noir também estava presente no filme neonoir, com exce- ção do elemento femme fatale, que não compõe um elemento da trama narrativa de Cães de Aluguel. Contudo, muitos pontos em comum podem ser destacados entre as produções analisadas especificamente, embora tenham sido lançadas em épocas distintas, o que torna notória a influência do noir clássico no cinema contemporâneo.

A temática criminal foi abordada de maneira diferente nas duas produções, entretanto manteve a sua característica de representar realidades através da validação de imaginários. No noir clássico, esse elemento exercia essa função devido ao período conturbado que a sociedade americana vivenciava. Em Pacto Sinistro, percebemos as personagens ambíguas, os ambientes claustrofóbicos e sombrios característicos das tramas do período clássico e que buscavam representar a insegurança da população e denunciar as "marcas" deixadas pela guerra. Já em Cães de Aluguel, embora teóricos como Baptista (2010) discordem, é possível que, através da sua insistência em temas como tráfico de drogas e a utilização exagerada da violência, Tarantino tenha representado ficcionalmente situações presenciadas pela sociedade da época.

Outro ponto importante a se destacar é a representatividade da violência para os dois períodos do noir. Tanto no clássico quanto no moderno ela é utilizada exaustivamente e vem acompanhada de um grande simbolismo nas produções. Em Pacto Sinistro, a cena da luta entre os protagonistas simboliza o desfecho da "briga" interior de Guy e da história, enquanto em Cães de Aluguel a utilização exagerada da violência através das cenas de tortura, tiroteios e brigas é efetuada por personagens que representam uma releitura dos tipos masculinos e durões prota- gonistas do noir clássico, gênero influenciado diretamente pela literatura hard-boiled ${ }^{8}$, conforme Silver e Ursini (2004).

Pacto Sinistro traz muitas características do cinema expressionista alemão, como os ambientes sombrios e os motivos iconográficos que dão sentido diferenciado a trama: a exemplo da escada, do isqueiro e da lente que reflete o assassinato de Mirian. Hitchcock utilizou muitos recursos para dar sentido a esta narrativa clássica. Mencionando a influência da psicanálise, temos a composição da personalidade complexa e doentia de Bruno. A influência também está presente em Cães de Aluguel, bem evidente nos atos psicopatas de Mr. Blonde.

A narrativa não linear e desfragmentada de Cães de Aluguel procede do cinema moderno, porém esta produção soube se valer das técnicas do filme noir para compor sua estrutura também nesse sentido. Os flashbacks e a narração em off, elementos utilizados na trama, foram herdados do noir clássico.

Duas grandes obras foram analisadas por este trabalho: Pacto Sinistro é um clássico do noir dirigido pelo mestre Alfred Hitchcock que, sem dúvida, emprestou todo seu talento a este suspense, que é um marco no cinema. Cães de Aluguel, filme neonoir dirigido por Quentin Tarantino, traz muitas características do noir clássico e é considerado uma obra inovadora devido a sua estrutura narrativa moderna e, ao mesmo tempo, inspirada no cinema clássico.

Destaca-se, ainda, que os filmes escolhidos trazem a responsabilidade de representar produções do período noir clássico e noir contemporâneo, por isso foram eleitos filmes considerados emblemáticas por sua qualidade e representação de gênero.

Neste trabalho buscamos destacar que os filmes 
noir e neonoir vão muito além da função de apenas entreter. Através de suas características inovadoras para época em que o noir surgiu e até mesmo para agora, eles continuam validando imaginários sobre a principal temática das produções, pois mantêm vivas na memória do público figuras imaginárias repletas de significados.

\section{Referências}

AUGUSTI, Alexandre Rossato. Cinema Noir: As marcas da morte e do hedonismo na atualização do gênero. 2013. 287 f. Tese (Doutorado em Comunicação Social) - Faculdade de Comunicação Social, PUCRS, Porto Alegre, 2013.

AUMONT, Jacques. A imagem. Campinas: Papirus, 2005.

AUMONT, Jacques; MARIE, Michel. Dicionário teórico e crítico de cinema. Campinas: Papirus, 2003.

BAPTISTA, Mauro. $\mathbf{O}$ cinema de Quentin Tarantino. Campinas: Papirus, 2010.

BORDE, Raymond; CHAUMETON, Etienne. Panorama del cine negro. Buenos Aires: Ediciones Losange, 1958.

HEREDERO, Carlos F.; SANTAMARINA, Antônio. El cine negro: maduración y crisis de la escritura clásica. Barcelona: Paidós, 1996.

MAFFESOLI, Michel. O imaginário é uma realidade.

Revista Famecos: mídia, cultura e tecnologia. Porto Alegre: Edipucrs, n. 15, ago. 2001.
MASCARELLO, Fernando. Film Noir. In: MASCARELLO, Fernando (org.). História do cinema mundial. Campinas: Papirus, 2006.

MATTOS, A. C. de Gomes de. 0 outro lado da noite: film noir. Rio de Janeiro: Rocco, 2001.

NAZÁRIO, Luiz. De Caligari a Lili Marlene: Cinema Alemão. São Paulo: Global, 1983.

ROSE, Diane. Análise de Imagens em Movimento. In: BAUER, Martin; GASKELL, George. Pesquisa Qualitativa com texto imagem e som: um manual prático. Petrópolis, RJ: Vozes, 2002.

SILVA, Juremir Machado. As Tecnologias do Imaginário. 2 ed. Porto Alegre: Sulina, 2006.

SILVA, Nathalia Lopes da. Cinema clássico e contemporâneo: diferenças, influencias e imaginário na temática do crime. Trabalho de conclusão de curso (Comunicação Social - Jornalismo). Universidade Federal do Pampa, São Borja, 2013. 71p.

SILVER, Alain; URSINI, James. Film noir. Lisboa: Taschen, 2004.

\section{Referências audiovisuais}

BENDER, Lawrence; TARANTINO, Quentin. Cães de Aluguel (Reservoir Dogs) [filme]. Produção de Lawrence Bender, direção de Quentin Tarantino. EUA, 1992. 99 min. color. son

HITCHCOCK, Alfred. Pacto Sinistro (Strangers on a train) [filme]. Produção de Alfred Hitchcock, direção de Alfred Hitchcock. EUA, 1951. 101 min. preto e branco. son.

\section{Notas}

1 Doutor em Comunicação Social pela Pontifícia Universidade Católica do Rio Grande do Sul (2013). Mestre em Comunicação e Informação pela Universidade Federal do Rio Grande do Sul (2005). Pós-doutor pelo Programa de Pós-Graduação em Comunicação e Informação da Universidade Federal do Rio Grande do Sul (2016). Professor do curso de Jornalismo da Universidade Federal do Pampa, unidade de São Borja (Universidade Federal do Pampa, campus São Borja. Rua Vereador Alberto Benevenuto, 3200. Passo. Cep: 97670-000 - São Borja, RS). E-mail: alexandreaugusti@unipampa. edu.br.

2 Mestranda em Mestrado Profissional em Comunicação e Indústria Criativa pela Universidade Federal do Pampa (2017). Especialista em Comunicação e Semiótica pela Universidade Estácio de Sá (2014). Graduada em Comunicação Social pela Universidade Federal do Pampa (2013). (Universidade Federal do Pampa, campus São Borja. Rua Vereador Alberto Benevenuto, 3200. Passo. Cep: 97670-000 - São Borja, RS). E-mail: nathalials.cn@ gmail.com.

30 presente trabalho tem base nas investigações e análise realizadas para a construção do Trabalho de Conclusão de Curso de Nathalia Lopes da Silva, sob orientação do Prof. Alexandre Rossato Augusti. O referido TCC é intitulado Cinema clássico e contemporâneo: diferenças, influências e imaginário na temática 
do crime (Silva, 2013). Parte, ainda, das investigações realizadas por Augusti (2013), no desenvolvimento de sua tese, período em que contou com bolsa sanduíche Capes durante o estágio realizado na Università degli Studi di Salerno (Itália).

4 Mascarello utiliza o termo para designar imagens de objetos como janelas (o quadro dentro do quadro), relógios, escadas, espelhos que recorrentemente aparecem nos filmes noir, e marcam uma das influências do expressionismo alemão.

5 Definição do flashback: "Sendo a ordem dos planos de um filme indefinidamente modificável, é possível, em particular, em um filme narrativo, fazer suceder a uma seqüência, outra seqüência, que relata acontecimentos anteriores; dir-se-á, então, que se 'volta atrás' (no tempo)" (Aumont; Marie, 2003, p. 131).

6 Somente as personagens com os nomes citados entre parênteses têm sua verdadeira identidade revelada na trama, as demais são identificadas apenas pelos codinomes.

7 Coluna que contém o conteúdo verbal e sonoro. $O$ conteúdo verbal também é sonoro, então optamos por apontar as duas dimensões já que o sonoro faz referência também aos outros elementos, como música instrumental ou não, ruídos, etc.

8 Segundo Silver e Ursini (2004), o noir deve seu poder verbal à escola de escrita hard-boiled, responsável pelas histórias de detetive da literatura de ficção criminal americana e que trabalha com temas relacionados à violência e ao sexo.

219 PORTO ALEGRE | v. 22 | n. 38 | 2017 | p. 209-219 Sessões do Imaginário 